\title{
Catastrophism through the Ages, and a Cosmic Catastrophe at the Origin of Civilization
}

\author{
Martin B Sweatman* \\ University of Edinburgh, $U K$ \\ *Corresponding author: Martin B Sweatman, School of Engineering, University of Edinburgh, Mayfield Road, Edinburgh, UK \\ Submission: 侮 September 22, 2017; Published: 侮 November 03, 2017
}

\begin{abstract}
Developments in the Earth Sciences over the last decade point towards a great cosmic catastrophe at the onset of the Younger Dryas period, towards the end of the Paleolithic. It has been suggested this event was caused by a collision with a swarm of comet fragments, consistent with the theory of Coherent Catastrophism. Earlier this year, it was shown how symbols at the ancient archaeological site of Göbekli Tepe can be interpreted as supporting this view. This convergence of geochemical, astronomical and archaeological evidence has potentially profound consequences for our understanding of the emergence of civilization and ancient history.
\end{abstract}

\section{Catastrophism through the Ages}

The idea that the Earth has been subject to tremendous catastrophes within the time span of human civilization originates with the earliest myths and religions [1]. All over the World, cultures have expressed their version of a great fire, or conflagration, and a great flood, or deluge. Typically, they are associated with divine retribution, fire-breathing, flying serpents and sea-monsters, heroic battles and tales of survival. Wherever people have lived, these myths have lived with them. In Western scholarship, the debate concerning the possibility that such mythological disasters have a basis in reality or are instead imagined, can be traced back to at least as far as Plato and his student Aristotle [2]. Plato recounts the destruction of Atlantis and the Phaethon myth, thereby promoting Catastrophism, while Aristotle argues for unchanging celestial spheres that support the sun, moon and planets, thereby promoting only gradual changes on Earth, i.e. gradualism.

But the modern view of catastrophism developed primarily out of the scientific resurgence in Western Europe after the renaissance [2]. Modern concepts in geology and evolutionary biology developed alongside those of mathematics and astronomy, all the time putting distance between science and religion. Copernicus re-established the idea of a heliocentric universe in 1543 against the teachings of the Catholic Church which had adopted Aristotle's geocentric paradigm of the sun, moon and planets supported by harmonious celestial spheres [3]. Therefore, despite promoting catastrophes via 'God's will', the universe was essentially perfect in it and did not suffer cosmic catastrophes through natural causes, according to the Church. Giordano Bruno took the Copernican idea further to propose that the stars are simply very distant suns, orbited by their own planets perhaps supporting life. He was burned at the stake in Rome in 1600 for this and other views contrary to Catholic doctrine. Galileo also suffered long-term house arrest, from 1633 to his death in 1642, at the hands of the Catholic Church for supporting heliocentrism. Against this backdrop, it is understandable that scientists of the age were keen to ensure their discoveries were consistent with Catholic teachings.

Building on Tycho Brahe's and Galileo's observations, and Kepler's laws of planetary motion, Newton published his seminal Principia in 1687 which described a mechanical universe evolving according to unchanging Laws of Motion and Universal Gravitation [4]. Using his theory, he was able to provide a unified description of planetary, lunar and cometary motion, and finally confirmed the Copernican heliocentric model of the solar system. While his mechanics supported a view of fixed planetary orbits, consistent with gradualism and his Christian beliefs, it also offered a catastrophic mechanism via Earth's interaction with comets. Indeed, his student, and successor to the Lucasian Chair of Mathematics at Cambridge, William Whiston, proposed in 1696 that comets were responsible for past catastrophes, including Noah's Flood [5]. Edmund Halley, after whom the famous comet is named, also held this view.

James Hutton, often called the father of modern geology, advanced the gradualist paradigm in 1785 through his observations and theories of sedimentation and erosion [6]. He held that Earth's surface changed only very slowly over geological time through processes that are evident today, a concept later called uniformitarianism. This was in contrast to the earlier flood geology that attempted to explain geological observations in biblical terms. Georges Cuvier, often called the father of paleontology, on the other hand, did not accept the gradualist paradigm. Through his 
observations of sedimentary strata containing abrupt changes in the fossil record, he proposed in 1812 a theory of extinctions and episodes of catastrophic change at Earth's surface [7].

But Charles Lyell, an influential geologist, supported Hutton's gradualist interpretation of change [8]. In his three volume work Principles of Geology published between 1830 and 1833, he argued that sudden changes in geological strata, and therefore abrupt changes in the fossil record, were an illusion generated by wholesale erosion of strata over geological timescales. Moreover, catastrophic changes required speculation about forces and mechanisms that are not currently observed, and therefore run contrary to the principle of uniformitarianism.

With a copy of Lyell's Principles on board the Beagle, Darwin ventured to the Southern Ocean to find evidence for this theory of natural selection. After his return, a committed gradualist, he published his Origin of Species in 1859 [9]. This was a decisive move in favor of gradualism. There was now a mutually consistent gradualistic framework, with Newton's mechanical universe that ran like clockwork, Hutton and Lyell's uniformitarian geology, and Darwin's biological evolution. Moreover, observations of comets showed their nuclei were quite small, and there were too few of them to provide a threat to Earth, especially on the timescale of human evolution. Whether, or not, this gradualistic paradigm supported the Christian doctrine depended on your point of view. On the one hand, it supported the view that catastrophes on human timescales could only occur through God's will. However, it also supported the view that God was no longer needed at all to explain the workings of the Universe, except perhaps as an initial creator, and that the Bible could not be trusted for historical accuracy. But this initial divergence of science from religion was quite limited. Christianity maintained a powerful hold over the establishment, and Darwin faced considerable criticism from those who could not accept evolution through natural law, rather than God's hand, and specifically the evolution of man from ape. The gradualistic paradigm solidified further well into the $20^{\text {th }}$ Century. First Gregor Mendel and then Avery and colleagues and Crick and Watson provided the mechanism for biological evolution; the inheritance of genes encoded in molecular DNA [10-12]. Darwin's theory of evolution through natural selection was now firmly established. Although it still did not demand a gradualistic basis, Darwin's support for gradualism was very influential. By the 1950s, a modern synthesis of Darwinism had developed in which slow changes in the environment, consistent with Hutton's uniformitarian principle of geology, provoked equally slow changes in species through natural selection $[13,14]$. That this gradual change in the biosphere was not reflected in the fossil record did not seem to matter. Nevertheless, gradualism was now the dominant paradigm, and catastrophism was generally the reserve of supposed cranks. Confirmation of the slow creeps of continents in the mid-60s, i.e. continental drift though plate tectonics provided further support to the gradualistic paradigm, and another mechanism for the diversification of species.

The intervention of Immanuel Velikovsky only served to reinforce this dominance. On the basis of his expertise in psycho- analysis, he proposed in 1950 there had been major catastrophes on the time scale of human civilization, and also proposed a revisionist version of history to account for them [15]. By themselves, these ideas could have been worthy of debate, however he coupled his theory with an un-physical mechanism; that part of Jupiter had been ejected as a comet, and collided with Earth before being transformed into Venus. While not taken seriously by the academic community generally, his ideas took hold within the public imagination.

However, in the early 1970s Eldridge and Gould proposed their theory of punctuated equilibrium to account for the abrupt changes seen in the fossil record, which it was now recognized were not in fact an artifact of slow geological processes [16]. This was supposedly a modification of the modern synthesis, and therefore of Darwinism, that allowed periods of rapid change in speciation together with rapid changes in the environment. Although the novelty of this idea continues to be debated within that research community, in that many paleontologists and evolutionary biologists argue that the new synthesis and even Darwinism already allowed for rapid changes in the rate of speciation on geological timescales, the key point is that it recognizes that a complete theory of biological evolution must cater for mass extinctions and rapid bursts in evolution. Although catastrophism was not thought necessary by most, at the time, to explain these rapid bursts of evolution and extinction events, the tide had clearly turned.

Furthermore, by 1980 it was known that near-Earth space was teeming with asteroids with a wide range of sizes. Indeed, the Asteroid Belt between Mars and Jupiter contained objects up to $900 \mathrm{~km}$ in diameter. Moreover, impact craters on the moon and inner solar system planets confirmed a similar impact history for Earth, even if craters on Earth remained relatively elusive. Catastrophic mechanisms were now easy to provide if evidence on the ground required them.

Everything changed in 1980 when Alvarez et al. proposed a massive asteroid impact at the Cretaceous-Tertiary boundary that ended the age of dinosaurs [17]. Their evidence was compelling, especially a global iridium anomaly at the geological boundary. When the Chicxulub crater, at $180 \mathrm{~km}$ in diameter, was located off the Yucatan peninsula, the case was practically confirmed. Earth was under threat after all, and catastrophism via cosmic events was revived. Today, the debate has moved on to the causes of major catastrophes and extinction-level events, and in particular the relative importance and correlation between cosmic impact and massive volcanism [18]. But the possibility that more recent extinction-level catastrophes could have occurred within the time span of human civilization as a result of cosmic impacts (since it is clear there have been no recent super-volcanic eruptions since Toba) is generally thought to be negligible, and dismissed by many academics.

This, despite the famous Shoemaker-Levy 9 event of 1994 in which a comet impacted Jupiter. The comet, fragmented by Jupiter's tidal forces into a long string of over 20 large pieces, collided with 
Jupiter to produce intense surface explosions, each large enough to have devastated Earth's biosphere, in the short space of a few days. Once again, this event challenged the prevailing gradualistic view: here was a massive collision of a comet with a planet of the solar system within our own lifetime. Clearly, these events could no longer be considered exceptionally rare, at least for Jupiter. Gradualistic views were no longer tenable, you might think, as cosmic catastrophism had been proven to occur. But, of course, it can be argued that Jupiter's gravity places it at special risk and that the same risks simply don't apply to Earth. Indeed, one can argue that Jupiter shields Earth from such violent events by 'mopping up' errant comets.

To summarize the debate, until the 1970s science had provided the ammunition to separate itself from the catastrophes of myth of religion. But over the next quarter century a rapid reversal occurred with the realization that (i) the fossil record really does exhibit abrupt extinctions followed by rapid bursts of evolution, (ii) near-Earth space contains millions of hazardous bodies, and (iii) such catastrophic impacts have been observed on Jupiter in our own lifetime.

\section{A Catastrophe at The Origin of Civilization}

Despite all this, the possibility that human civilization could have been significantly affected by such events is still denied by many to the present day. Although a risk on the timescale of millions of years is recognized, it is generally considered implausible that a global cosmic catastrophe could have occurred over the last, say, ten or twenty thousand years. The argument given to support this denial is usually probabilistic; assuming the number and size distribution of near-Earth asteroids is fixed over time, a major cosmic collision within the timescale of human civilization remains unlikely; not impossible of course, just very unlikely. But notice the assumption here; is it really reasonable to assume that the population of asteroids and comets in near-Earth space has not changed significantly over the course of human civilization? What evidence is there for this?

Recent research indicates, almost certainly, that the above assumption is incorrect. Over the last two decades, it has become clear that the Taurid meteor complex is very large, very old, and has been generated by the break-up of a giant comet in the inner solar system. Moreover, this fragmentation process would have resulted in a greatly enhanced risk of bombardment for Earth, which is likely to be reflected in the archaeological record [19]. Strong evidence for this comes in two main forms [20]. First, the orbits of some of the largest near-Earth objects in orbits similar to that of comet Encke, which is associated with the Taurid meteor complex, are highly correlated, indicating that most of them are fragmentation products of a single very large and very old progenitor comet [19]. Second, the mass of the zodiacal dust cloud (to which comets trapped in the inner solar system eventually decay) cannot be accounted for by the cometary population currently observed; it instead points strongly towards the input of a very large cometary mass into the inner solar system over the timescale of human civilization or somewhat longer [21].

In addition, geochemical evidence, accrued over the last decade, points very strongly to a catastrophic cosmic encounter with an asteroid or comet at the onset of the Younger Dryas period $[22,23]$. Indeed, recent evidence from the last few years from three independent research groups has revealed a platinum anomaly that extends at least across North America, Greenland and North-West Europe, coeval with other evidence for a cosmic impact, including impact spherules, magnetic grains and nano diamonds [24-26]. Although disputed by several prominent and vocal research groups, their counter-arguments are generally weak to non-existent while evidence from independent research groups continues to accumulate [27-34].

Finally, and quite astonishingly, this event appears to be recorded in stone by its survivors in the Fertile Crescent at Göbekli Tepe, southern Anatolia, currently perhaps the World's most important archaeological site. With Dimitrios Tsikritsis, I recently provided an interpretation of symbolism at Göbekli Tepe, a site that appears at the nexus of the Neolithic revolution, consistent with the astronomical, geochemical and archaeological evidence [35,36]. Moreover, our statistical analysis of this interpretation indicates it is very likely to be correct. In particular,

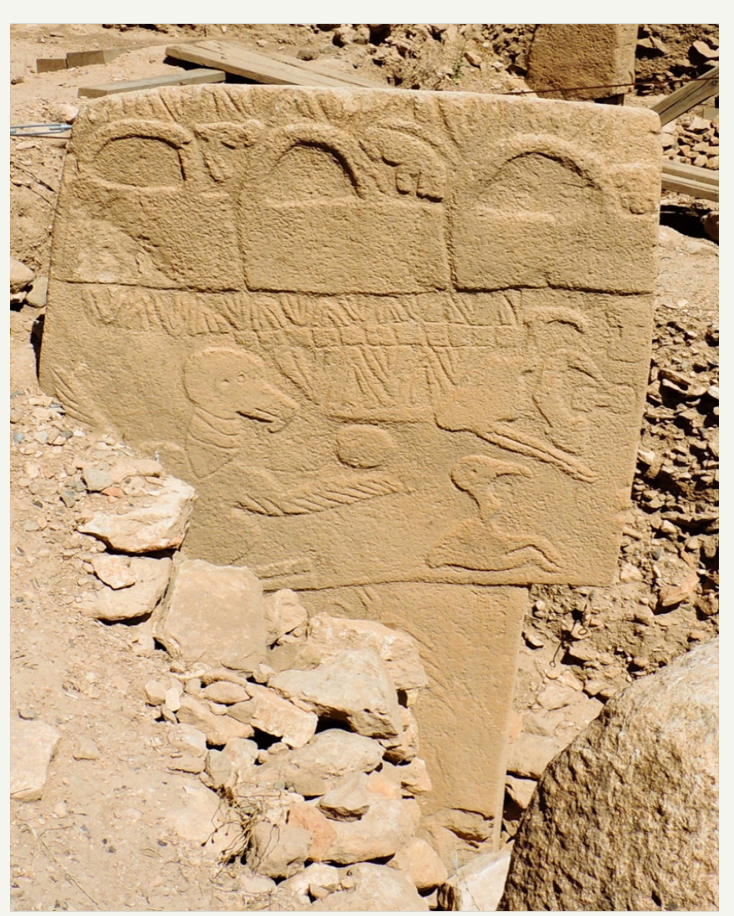

Figure 1: Pillar 43, the Vulture Stone, at Göbekli Tepe, embedded into the rough stone wall of enclosure D (courtesy of Alistair Coombs).

- Pillar 43 at Göbekli Tepe (Figure 1), popularly known as the Vulture Stone, can be interpreted as the date of the event (which agrees very well with the timing of the platinum anomaly in the Greenland GISP2 ice core at the onset of the Younger Dryas cooling [24]) encoded using precession of the equinoxes, with animal 
symbols representing specific constellations similar to those known today in Western Europe, thought to be acquired from the ancient Greeks.

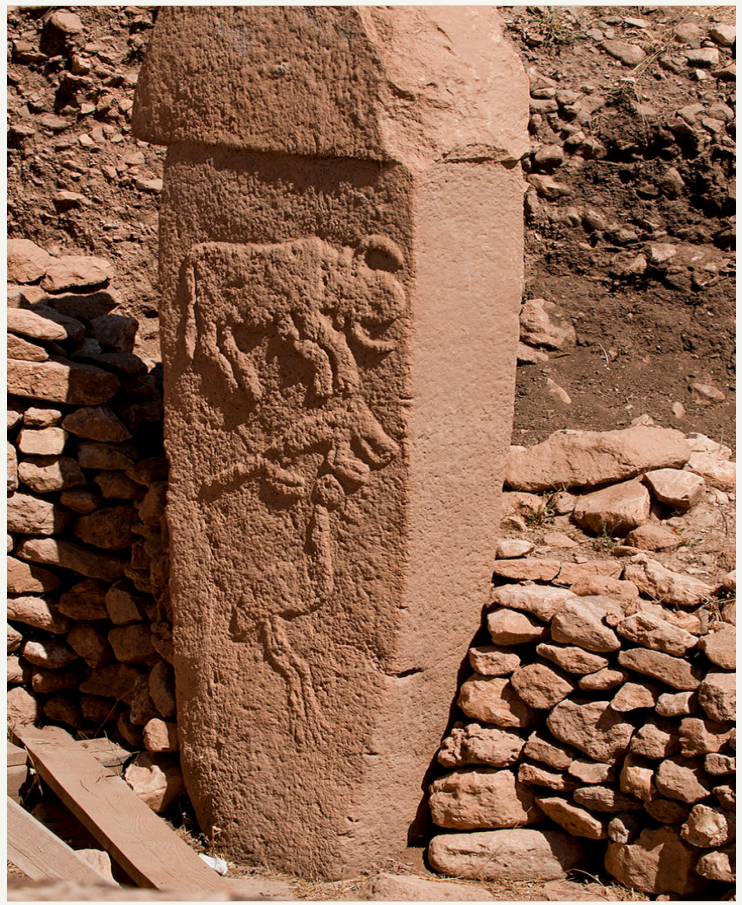

Figure 2: Pillar 2, Enclosure a of Göbekli Tepe (image by Teomancimit from Wikipedia).

- Pillar 2 at Göbekli Tepe (Figure 2) can be interpreted as an observation of the track of the radiant of the Northern Taurid meteor stream, also using animal symbols as constellations.

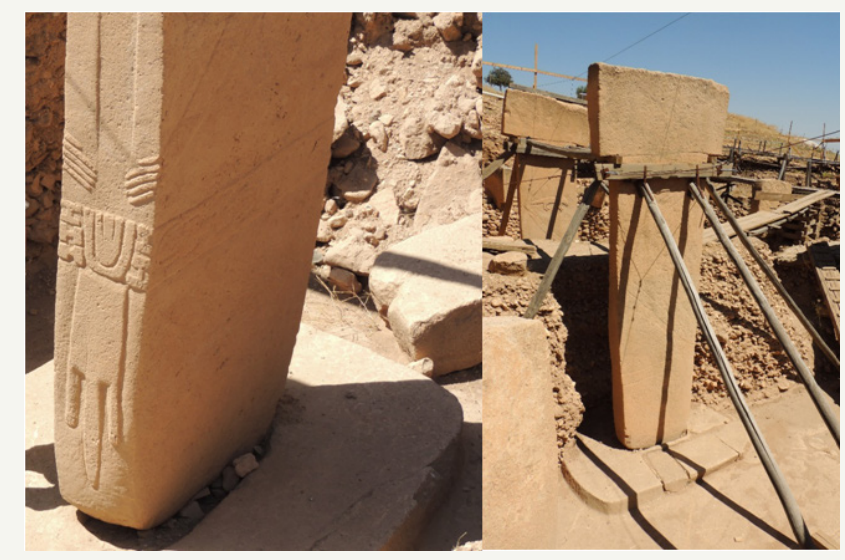

Figure 3: Left: Close-up of the bottom of Pillar 18. Right: Pillars 31 (foreground) and 18 (background) in Enclosure D at Göbekli Tepe (both courtesy of Alistair Coombs).

- Pillar 18, one of the main central pillars (Figure 3), can be interpreted as providing the mechanism of the event corresponding to the date on Pillar 43, i.e. an encounter with the Northern Taurids Specifically, its vulpine symbolism corresponds to the northern asterism of our Aquarius constellation, which in turn likely corresponds to the position of maximum intensity of Northern
Taurid meteors at the time of the event.

\section{Conclusion}

This convergence of the astronomical, geochemical and archaeological evidence suggests it is very likely that the theory of Coherent Catastrophism, pioneered by Victor Clube and Bill Napier in the Early 1980s, is correct $[37,38]$. The implications for archaeology and anthropology, at least, are profound, in that Coherent Catastrophism implies other catastrophic cosmic encounters with the Taurids, with a wide range of magnitudes, likely occurred both before and after this main event. Indeed, due to orbital precession of the Taurid complex, we can expect to observe an enhanced risk of bombardment to occur for a period of 500 years or so, due to overlap of two separate risk peaks, every 3000 years over the Holocene, although that enhanced risk might have decayed, along with the offending giant comet, towards background levels today.

Normally, any evidence of cosmic catastrophes over the course of human civilization is interpreted as being the result of other causes. Clearly, it is now important that existing scientific data indicating pre-historic and historical catastrophes, including major and correlated episodes of cultural transition, civilization collapse, population migration, climate change, earthquake, war, famine, pestilence and conflagration and flooding, is re-assessed to properly consider cosmic bombardment as a possible causal mechanism. Moreover, it appears the capabilities of people in the Fertile Crescent at the Paleolithic to Neolithic transition have been underestimated, and a key influence on the Neolithic revolution might have been over-looked.

\section{References}

1. Piccardy L, Masse WB (2007) Myth and Geology. The Geological Society, London.

2. Palmer T (2003) Perilous Planet Earth. Cambridge University press, USA.

3. Copernicus N (1543) De revolutionibus orbium coelstium.

4. Newton I (1687) Philosophiae Naturalis Principia Mathematica. Royal Society Press, London.

5. Whiston W (1696) A new theory of the earth. London.

6. Hutton J (1788) Theory of the Earth. Transactions of the Roral Society of Edinburgh 1: 209-304.

7. Cuvier G (1812) Recherche sur les ossemens fossiles de quadrupedes, Paris.

8. Lyell C 1830 Principles of Geology. Vol 1, John Murray, London.

9. Darwin C (1859) On the Origin of Species. John Murray, London.

10. Mendel G (1866) Versuche Uber Pflanzen-Hybriden. Verhandlungen des naturforschenden Vereines in Brünn IV. pp. 3-47.

11. Avery O, Macleod CM, McCarty M (1944) Studies on the chemical nature of the substance inducing transformation of pneumococcal types: induction of transformation by a deoxyribonucleic acid fraction isolated from pneumococcus type III. J Exp Med 79(2): 137-158.

12. Crick F, Watson JD (1953) Molecular structure of nucleic acids: a structure for deoxyribose nucleic acid. Nature 171(4356): 737-738.

13. Dobzhansky T (1937) Genetics and the Origin of Species, Columbia 
University Press, New York, USA.

14. Mayr E (1942) Systematics and the Origin of Species from the viewpoint of a zoologist. Columbia University Press, USA.

15. Velikovsky E (1950) Worlds in Collision. Macmillan Publishers, Hyderabad, India.

16. Eldredge N, Gould SJ (1972) Punctuated equilibria: an alternative to phylectic gradualism. In: Schopf TJM (Ed.), Models in Paleobiology. Freeman Cooper, San Francisco, USA.

17. Alvarez LW, Alvarez W, Asaro F, Michel HW (1980) Extraterrestrial causes the Cretatious-Tertiary extinction. Science 208(4448): 1095-1108.

18. Keller G, Kerr AC (2014) Volcanism, impacts and mass extinctions: causes and affects. The Geological Society of America, USA.

19. Napier WM (2010) Paleolithic extinctions and the Taurid Complex. Monthly Notices of the Royal Astronomical Society 405(3): 1901-1906.

20. Bailey M, Asher D, Napier B, Steel D (2015) Centaurs as a hazard to civilization. Astronomy \& Geophysics 56: 24-30.

21. Napier WM (2001) Temporal variation of the zodiacal dust cloud. Mon Not R Astr Soc 321: 463-470.

22. Firestone RB, West A, Kennett JP, Becker L, Bunch TE, et al. (2007) Evidence for an extraterrestrial impact 12,900 years ago that contributed to the mega faunal extinctions and the Younger Dryas cooling. PNAS 104(41): 16016-16021.

23. Kennett DJ, Kennett JP, West A, Mercer C, Hee SSQ, et al. (2009) Nanodiamonds in the younger dryas boundary sediment layer. Science 323(5910): 94.

24. Petaev MI, Huang SC, Jacobsen SB, Zindler A (2013) Large Pt anomaly in the Greenland ice core points to a cataclysm at the onset of Younger Dryas. Proc Natl Acad Sci U S A 110(32): 12917-12920.

25. Andronikov AV, Subetto DA, Lauretta DS, Andronikova IE, Drosenko DA et al. (2014) In Search for Fingerprints of an Extraterrestrial Event: Trace Element Characteristics of Sediments from the Lake Medvedevskoye (Karelian Isthmus, Russia). Doklady Earth Sciences 457(1): 819-823.

26. Moore CR, West A, Lecompte MA, Brooks MJ, Daniel IR, et al. (2017) Widespread platinum anomaly documented at the Younger Dryas onset in North American sedimentary sequences. Sci Rep 7: 44031.

27. Holliday VT, Surovell T, Meltzer DJ, Grayson DK, Boslough M, et al. (2014)
The Younger Dryas impact hypothesis: a cosmic catastrophe. JQS 29(6): 515-530.

28. Meltzer DJ, Holliday VT, Cannon MD, Miller DS (2014) Chronological evidence fails to support claim of an isochronous widespread layer of cosmic impact indicators dated to 12,800 years ago. PNAS 111(21): E2162-E2171.

29. Pinter N, Scott AC, Daulton TL, Podoll A, Koeberl C, et al. (2011) The Younger Dryas impact hypothesis: A requiem. Earth-Science Reviews 106(3-4): 247-264.

30. Van Hoesel A, Hoek WZ, Braadbaart F, Van Der Plicht J, Pennock GM, et al. (2012) Nanodiamonds and wildfire evidence in the Usselo horizon postdate the Allerod-Younger Dryas boundary. Proc Natl Acad Sci U S A 109(20): 7648-7653

31. Firestone RB, West A, Bunch TE (2010) Confirmation of the Younger Dryas boundary (YDB) data at Murray Springs, AZ. Proc Natl Acad Sci USA 107(26): E105-E105.

32. Wittke JH, Bunch TE, Kennett JP, Kennett DJ, Culleton BJ, et al. (2013) Reply to van Hoesel et al.: Impact-related younger dryas boundary nano diamonds from The Netherlands. Proc Natl Acad Sci U S A 110(41): E3897-E3898.

33. Kennett JP, Kennett DJ, Culleton BJ, Tortosa JEA, Bischoff JL, et al. (2012) Independent evaluation of conflicting micro spherule results from different investigations of the Younger Dryas impact hypothesis. PNAS 109(44): E2960-E2969.

34. Mahaney WC, Keiser L, Krinsley DH, West A, Dirszowsky R, et al. (2014) Recent Developments in the Analysis of the Black Mat Layer and Cosmic Impact at $12.8 \mathrm{ka}$. Geografiska Annaler Series a-Physical Geography 96(1): 99-111.

35. Sweatman MB, Tsikritsis D (2017a) Comment on More than a vulture: response to Sweatman and Tsikritsis. Mediterranean Archaeology and Archaeometry 17: 63-70.

36. Sweatman MB, Tsikritsis D (2017b) Decoding Gobekli Tepe with Archaeoastronomy: What does the fox say? Mediterranean Archaeology and Archaeometry 17: 233-250.

37. Clube SVM, Napier WM (1984) The microstructure of terrestrial catastrophism. Mon Not R astr Soc 211: 953-968.

38. Clube SVM, Napier WM (1982) The Cosmic Serpent. Faber and Faber Limited, London. 